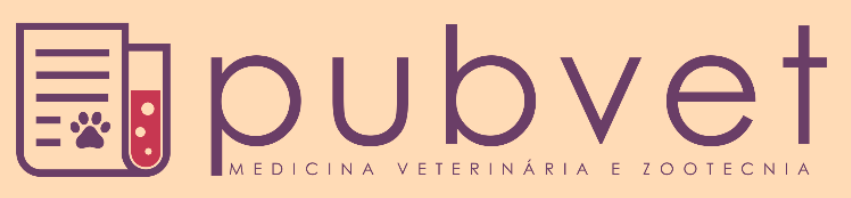

https://doi.org/10.31533/pubvet.v15n10a938.1-15

\title{
Métodos in situ e in vitro utilizados para avaliação de alimentos e dietas de ruminantes
}

\author{
Juraci Marcos Alves Suassuna ${ }^{1 *} \bullet \mathbb{C}$, Ariosvaldo Nunes de Medeiros ${ }^{2} \odot \mathbb{E}$, Beatriz Dantas Oliveira \\ Fernandes $^{30}$ (D), Daniel Ribeiro Menezes ${ }^{\circ}$ (D), Alberício Pereira de Andrade ${ }^{5}$ (D), Marcelo de \\ Oliveira Alves Rufino 60 \\ ${ }^{I}$ Zootecnista da Universidade Federal da Paraíba, Departamento de Zootecnia. Areia-PB Brasil. \\ ${ }^{2}$ Professor da Universidade Federal da Paraíba, Departamento de Zootecnia. Areia-PB Brasil. \\ ${ }^{3}$ Pós doutoranda da Universidade Federal da Paraíba, Departamento de Zootecnia. Areia-PB Brasil. \\ ${ }^{4}$ Professor da Universidade Federal do Vale do São Francisco, Departamento de Pós-Graduação em Ciências Veterinárias no Semiárido. Petrolina-PE Brasil. \\ ${ }^{5}$ Professor da Universidade Federal do Agreste de Pernambuco, Departamento de Zootecnia. Garanhuns-PE Brasil. \\ ${ }^{6}$ Universidade Federal da Paraíba, Areia-PB Brasil. \\ *Autor para correspondência, E-mail: juracizootec@hotmail.com
}

Resumo. Nos sistemas de produção de ruminantes a alimentação pode responder por 60 a $70 \%$ dos custos da atividade, sendo assim, a avaliação nutricional dos alimentos e a formulação de dietas balanceadas, que atendam às exigências dos animais representam um importante desafio na produção pecuária. Diversos métodos têm sido usados para avaliar a modulação da fermentação ruminal e estimar as características da degradação de alimentos e dietas destinadas à alimentação de ruminantes. Esses métodos envolvem a medição do desaparecimento do substrato durante a incubação no rúmen in situ, no líquido ruminal tamponado (in vitro) e são principalmente medidas de ponto final. Além disso, é possível avaliar a cinética da degradação através da medição das diferenças nos resíduos em diferentes tempos de incubação. A avaliação do valor nutricional de alimentos e dietas também é possível ser feita por meio da utilização de técnicas que medem a produção de gás. Essas técnicas medem o aparecimento de produtos da fermentação ruminal, tais como os gases dióxido de carbono $\left(\mathrm{CO}_{2}\right)$ e metano $\left(\mathrm{CH}_{4}\right)$, ácidos graxos de cadeia curta, amônia e a biomassa microbiana. Objetivou-se com essa revisão descrever os principais métodos in situ e in vitro utilizados para avaliar alimentos para ruminantes.

Palavras-chave: Fermentação ruminal, produção de gás, digestibilidade

\section{In situ and in vitro methods used to evaluate food and diets of ruminants}

\begin{abstract}
In ruminant production systems, feeding can account for 60 to $70 \%$ of the costs of the activity, thus, the nutritional assessment of food and the formulation of balanced diets that meet the requirements of animals represent an important challenge in livestock production. Several methods have been used to evaluate the modulation of rumen fermentation and to estimate the degradation characteristics of food and diets intended for feeding ruminants. These methods involve measuring the disappearance of the substrate during incubation in the rumen (in situ), in the buffered rumen liquid (in vitro) and are mainly endpoint measurements. In addition, it is possible to evaluate the degradation kinetics by measuring the differences in residues at different incubation times. The assessment of the nutritional value of foods and diets is also possible through the use of techniques that measure gas production. These techniques measure the appearance of rumen fermentation products, such as carbon dioxide $\left(\mathrm{CO}_{2}\right)$ and methane $\left(\mathrm{CH}_{4}\right)$ gases, short-chain fatty acids, ammonia and microbial biomass. The aim of this review was to describe the main in situ and in vitro methods used to evaluate food for ruminants.
\end{abstract}

Keywords: Rumen fermentation, gas production, digestibility 


\title{
Métodos in situ e in vitro utilizados para evaluar alimentos y dietas de rumiantes
}

\begin{abstract}
Resumen. En los sistemas de producción de rumiantes, la alimentación puede representar del 60 al 70\% de los costos de la actividad, por lo que la evaluación nutricional de los alimentos y la formulación de dietas balanceadas, que satisfagan los requerimientos de los animales, representan un desafío importante en la producción ganadera. Se han utilizado varios métodos para evaluar la modulación de la fermentación ruminal y estimar las características de degradación de los alimentos y las dietas destinadas a la alimentación de rumiantes. Estos métodos implican medir la desaparición del sustrato durante la incubación en el rumen (in situ), en el líquido ruminal tamponado in vitro y son principalmente medidas de punto final. Además, es posible evaluar la cinética de degradación midiendo las diferencias en los residuos en diferentes tiempos de incubación. La evaluación del valor nutricional de los alimentos y las dietas también es posible mediante el uso de técnicas que miden la producción de gas. Estas técnicas miden la aparición de productos de fermentación ruminal, como los gases de dióxido de carbono $\left(\mathrm{CO}_{2}\right)$ y metano $\left(\mathrm{CH}_{4}\right)$, ácidos grasos de cadena corta, amoniaco y biomasa microbiana. El objetivo de esta revisión fue describir los principales métodos in situ e in vitro utilizados para evaluar alimentos para rumiantes.
\end{abstract}

Palabras clave: Fermentación ruminal, producción de gas, digestibilidad

\section{Introdução}

A avaliação nutricional dos alimentos e a formulação de dietas balanceadas, que atendam as exigências dos animais, representam um importante desafio na produção pecuária, uma vez que nos sistemas de produção, a alimentação pode responder por mais de $60 \%$ dos custos da atividade. Apesar disso, o fornecimento de uma dieta equilibrada nutricionalmente pode contribuir com a redução dos problemas ambientais, haja vista que a excreção de nutrientes não digeridos e a emissão de gases afeta o meio ambiente (Getachew et al., 2005).

Com isso, diversos esforços foram direcionados para o desenvolvimento e aprimoramento de técnicas que permitam a avaliação de alimentos e dietas que predizem com precisão, a ingestão e digestibilidade de alimentos. Essa digestibilidade pode ser avaliada usando métodos biológicos que simulam o processo de digestão dos alimentos (Getachew et al., 1998), os quais envolvem o uso direto de animais (métodos in vivo e in situ) e métodos laboratoriais, que simulam o ambiente ruminal e, seu processo de digestão utiliza líquido ruminal coletados de animais doadores (métodos in vitro), a exemplo da técnica de Tilley \& Terry (1963) ou o método de Menke et al. (1979).

Os métodos biológicos são mais significativos na avaliação do valor nutritivo dos alimentos, visto que os microrganismos e as enzimas são mais sensíveis a fatores que influenciam a taxa e a extensão da digestão do que os métodos químicos (Van Soest, 1994). De um modo geral, para um método laboratorial ser considerado eficiente, ele deve ser reproduzível e correlacionar-se bem com os parâmetros medidos realmente in vivo. Assim, objetivou-se com essa revisão estudar os principais métodos in situ e in vitro utilizados na avaliação de alimentos e dietas para ruminantes.

\section{Métodos in situ de avaliação de alimentos para ruminantes}

A avaliação de alimentos através de técnicas in situ tem sido amplamente utilizada nos últimos anos, sendo provavelmente a técnica mais utilizada para determinação da degradabilidade de diferentes componentes químicos da dieta no rúmen (Dong et al., 2017). Chamada de diferentes nomes (in sacco, saco de náilon, saco de dacron, saco de pano), a técnica requer a incubação de uma pequena quantidade de alimento em sacos porosos, não degradáveis, suspensos no rúmen de um animal fistulado por diferentes períodos (Ørskov \& McDonald, 1979). Esses sacos são removidos em intervalos regulares, sendo a perda de peso plotada (geralmente em relação à matéria seca) e uma curva é ajustada aos pontos de dados resultantes (Williams, 2000).

A técnica in situ foi originalmente desenvolvida por (Quin et al., 1938) (citado por Huntingdon \& Givens (1995) and Pagella et al. (2018), que incubaram amostras de ração em sacos de seda no rúmen de ovinos fistulados para avaliar a degradabilidade de alimentos. Posteriormente, os sacos de seda foram 
substituídos por sacos de náilon (Rodriguez, 1968). Segundo Dong et al. (2017) existem dois métodos básicos para incubação de sacos de náilon no rúmen. No primeiro método, os sacos são colocados no rúmen ao mesmo tempo e recuperados em diferentes momentos (all in-gradually out method; AG), sendo referido em diversos estudos (Cobellis et al., 2015; Edmunds et al., 2012; Peyrat et al., 2014). No segundo método, os sacos são inseridos no rúmen em diferentes tempos e retirados em um único momento (gradually in-all out method; GA) e, também tem sido muito utilizado (Azarfar et al., 2013; Jonker et al., 2011; Xin \& Yu, 2013). Variações entre alimentos, animais e laboratórios podem ser observadas com a utilização destes métodos. No entanto, bancos de dados com um número suficiente de observações poderiam, pelo menos em parte, superar a falta de poder estatístico de um único estudo (St-Pierre, 2001).

As técnicas in situ baseiam-se no pressuposto de que o desaparecimento do substrato dos sacos representa a degradação real do substrato pelos microrganismos ruminais e suas enzimas. Contudo, várias questões não podem ser resolvidas completamente, já que nem todo o material que sai da bolsa foi previamente degradado, e parte do resíduo remanescente na embalagem não é realmente matéria não degradável de origem alimentar (Dijkstra et al., 2005). Na Tabela 1 são apresentados os principais fatores que podem resultar em erros na avaliação da degradabilidade in situ de alimentos. Alguns desses fatores serão discutidos mais detalhadamente a seguir.

Tabela 1. Fatores que afetam as técnicas in situ.

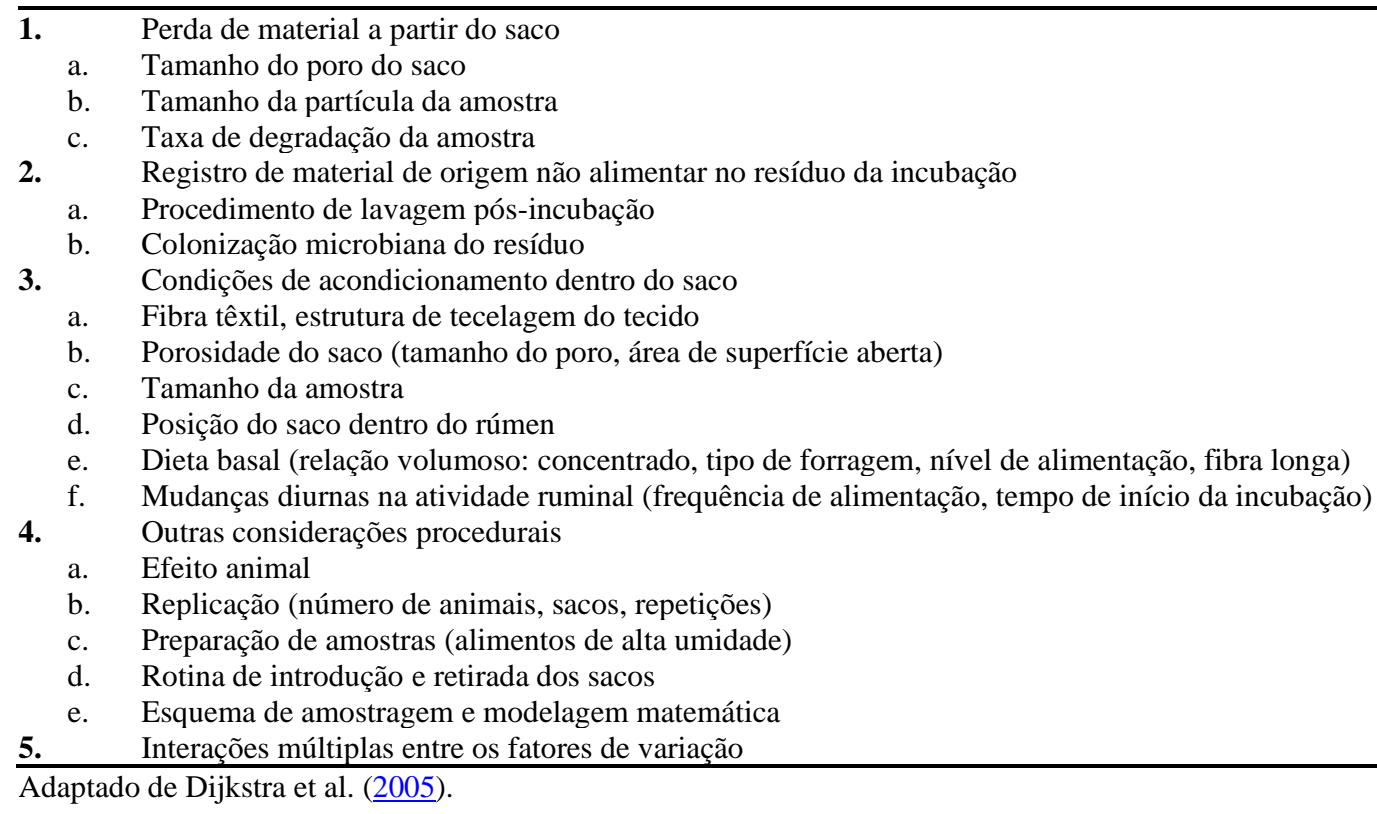

Conforme citado na tabela 1 , diversos fatores podem comprometer a avaliação da degradabilidade de alimentos in situ, dentre os quais podemos destacar os aspectos físicos dos sacos utilizados para incubação de amostras, como tamanho dos poros dos sacos (Lindberg \& Knutsson, 1981), tipo de sacos (Casali et al., 2009; Tagliapietra et al., 2012; Valente et al., 2011), tamanho de partícula da amostra (Damiran et al., 2008; Kuwahara et al., 2016; Michalet-Doreau \& Ould-Bah, 1992), relação tamanho da amostra: saco (Uden et al., 1974), o tipo de dieta basal (Lindberg, 1981), efeito animal (Ali et al., 2016; Nocek, 1988), procedimento de lavagem de sacos (Nocek, 1988) e, sequência de incubação dos sacos no rúmen (Nocek, 1985). Além de apresentarem efeitos isolados, esses fatores podem apresentar interações múltiplas, aumentando ainda mais o erro na estimativa da degradabilidade in situ dos alimentos.

No que diz respeito aos aspectos físicos dos sacos de incubação, é consenso que a estrutura do tecido para confecção dos sacos é de grande importância na avaliação de alimentos in situ (Huntingdon \& Givens, 1995), uma vez que pode afetar significativamente os valores de degradabilidade ruminal (Casali et al., 2009; Figroid et al., 1972). A propensão do pano do tecido para deformar pode levar a uma maior perda de partículas sob pressão, sendo espremidas através das aberturas flexíveis (Marinucci et al., 1992) e assim, pode superestimar os valores de degradabilidade, visto que a fração perdida 
frequentemente é associada ou confundida com a fração da matéria seca rapidamente degradável e prontamente solúvel no ambiente ruminal (Casali et al., 2009).

O AACRS (1990) sugeriu a utilização de sacos de poliéster para incubação in situ, devendo-se optar por usar malhas soldadas (monofilamentosa) e não tecida (multifilamentosa). Contudo, a maioria dos pesquisadores tem optado por usar sacos de náilon, sendo uma das razões para isto, o histórico relacionado ao repetitivo uso de sacos existentes (Huntingdon \& Givens, 1995). Avaliando a substituição do saco padrão F57 da ANKOM por sacos de náilon de porosidade de $50 \mu \mathrm{m}$ em análises de fibra insolúvel, Berchielli et al. (2001) encontraram menores teores de FDN nas fezes, quando utilizados sacos de náilon, que foram atribuídos à perda de amostra pelos poros do saco durante a extração com detergente. Resultados semelhantes foram obtidos por Casali et al. (2009) e Valente et al. (2011), ao compararem a perda de partículas por três tipos diferentes de tecidos, F57, TNT e náilon, corroborando que o náilon $(50 \mu \mathrm{m})$ possa não ser um tecido adequado para a confecção de sacos destinados à análise de componentes fibrosos insolúveis.

Carro et al. (1995) verificaram que além de influenciar no desaparecimento da dieta, o tamanho dos poros do saco pode afetar também a população microbiana no sistema e, consequentemente, a fermentação. Michalet-Doreau \& Ould-Bah (1992) e Nocek (1988) mostraram que a microbiota presente no interior dos sacos pode diferir daquela presente na digesta ruminal circundante, e isso é resultado das condições de armazenamento do alimento no interior do saco, podendo levar a diferenças na quantidade e na atividade dos microrganismos. Com isso, algumas interações digestivas negativas podem ocorrer no interior dos sacos de náilon (Sauvant et al., 1994). Outro ponto a ser destacado, é que pode ocorrer um armazenamento transitório de amido em células microbianas (bactérias e protozoários), podendo uma quantidade significativa de amido, incluído na matéria microbiana, permanecer no resíduo da bolsa (Offner et al., 2003).

Portanto, o tamanho dos poros e a área aberta do tecido utilizado para sacos in situ devem ser tais que permitam o influxo de agentes digestores e tampões e, ao mesmo tempo, evitem o efluxo de amostras não degradadas (Nocek, 1988), enquanto permite a remoção de produtos finais da degradação. O controle do efluente da amostra não degradada pode ser obtido reduzindo o tamanho de abertura dos poros dos sacos ou aumentando o tamanho médio de partícula do substrato (Huntingdon \& Givens, 1995).

O tamanho de partícula, por sua vez, tem sido considerado como um dos fatores chave na determinação da degradabilidade in situ de alimentos. Porém, de acordo com Nocek (1988), a definição do tamanho ideal de partículas para ensaios in situ não é tarefa fácil, em razão da escassez de informações sobre a associação entre digestão in vivo, in situ e tamanho de partículas. Tem-se verificado a ocorrência de aumento da taxa de digestão em decorrência da redução das frações do tamanho de partícula (Robles et al., 1980), podendo-se inferir que o aumento da exposição das frações digestivas ao ataque microbiano, devido a moagem, foi responsável por taxas de degradação mais rápidas. Alamouti et al. (2009) observaram que a redução do tamanho de partículas na dieta de ovinos afetou significativamente a cinética de degradação de forragem, mas não de concentrados e dietas mistas. Da mesma forma, Casali et al. (2008) verificaram um efeito mais pronunciado do tamanho de partícula, sobre as frações indigestíveis de alimentos e fezes bovinas, nos alimentos fibrosos em comparação aos alimentos concentrados e às fezes. Os autores observaram, ainda, uma relação diretamente proporcional entre o tamanho da partícula e o tempo crítico para obtenção da fração indigestível, ou seja, quanto maior o tamanho da partícula, maior o tempo necessário para se estimar acuradamente o teor de compostos indigestíveis.

O efeito animal é outra fonte de variação que deve ser considerada na avaliação da degradação in situ de alimentos, uma vez que pode haver diferenças pequenas, porém significativas, nas estimativas de degradação de rações se as amostras forem incubadas no rúmen de animais de raças e espécies diferentes. Visando observar essa fonte de erro da técnica, Ali et al. (2016) compararam a degradação ruminal in situ de silagens de milho e de capim, utilizando diferentes animais como fonte de variação. Os autores concluíram que o uso de três animais para incubação de silagem de capim em sacos de náilon foi suficiente para cobrir a variação existente entre animais, porém esse número de animais não foi suficiente para avaliar a degradação de silagem de milho. Segundo Huntingdon \& Givens (1995), para 
melhorar a precisão das medições, deve-se utilizar o mesmo tipo de animal para cada experimento, no mesmo estado fisiológico e mantido nas mesmas condições ambientais e de criação.

Além das variáveis discutidas acima, diversas outras fontes de erro podem comprometer a avaliação in situ de forrageiras e dietas utilizadas na alimentação de ruminantes, devendo-se estar atento a esses fatores para garantir estimativas acuradas da qualidade nutricional dos alimentos.

Apesar de muito utilizada e de proporcionar boas estimativas da digestibilidade de diferentes alimentos, as técnicas in situ convencionais requerem o uso de animais cirurgicamente preparados com uma fístula ruminal, levando a inúmeros questionamentos, do ponto de vista ético, a respeito do bemestar dos animais em experimentação. Em função disso, é constante a busca pelo desenvolvimento de técnicas alternativas que possam reduzir ou cessar os procedimentos que dependem da preparação cirúrgica.

Isso foi observado no trabalho publicado por Pagella et al. (2018), os quais desenvolveram uma técnica de saco de náilon intra-ruminal utilizando animais não fistulados para avaliar a degradabilidade ruminal de materiais vegetais. O princípio da técnica consiste em administrar oralmente uma série de sacos porosos contendo os alimentos de teste em diferentes momentos antes do abate, quando os sacos seriam removidos do rúmen para medição da degradabilidade. Foram realizados dois ensaios. No primeiro ensaio, os autores compararam a eficácia do design de três dispositivos anti-regurgitação, construídos a partir de abraçadeiras de náilon [1) Em forma de Z, ARD1; 2) em forma de Z duplo, $\mathrm{ARD} 2$; 3) em forma de guarda-chuva, ARD3], e observaram se curvas de degradação viáveis poderiam ser geradas usando feno de capim como substrato. No segundo, foram comparados outros três substratos (azevém perene, trevo vermelho e palha de cevada) utilizando sacos em dois formatos, planos e tetraédricos, equipados com dispositivos anti-regurgitação tipo ARD1. As curvas de degradação obtidas com esta técnica estavam amplamente de acordo com aquelas esperadas pelo método do saco de náilon convencional envolvendo animais fistulados. Também foi possível observar nessa técnica, que os sacos administrados por via oral tiveram mais liberdade para se mover em diferentes partes do conteúdo ruminal em comparação à técnica in situ convencional.

\section{Métodos de avaliação in vitro de alimentos e dietas para ruminantes}

\section{Técnicas de digestibilidade}

Estimativas da digestibilidade in vitro de alimentos ou dietas podem possibilitar aos nutricionistas predizer a digestibilidade in vivo dessas frações mediante equações de regressão, devido às fortes correlações existentes entre os resultados de ambas as técnicas (Silva et al., 2017).

- $\quad$ Método tradicional de Tilley \& Terry (1963)

A técnica de Tilley \& Terry (1963) foi uma das primeiras técnicas in vitro desenvolvidas e a mais usada para predizer a digestibilidade de forragens. Os autores avaliaram a digestibilidade de 148 herbáceas, de digestibilidades in vivo conhecidas, sendo 18 amostras de alfafa e trevo e 130 amostras de gramíneas, e confirmaram uma alta correlação entre os valores de digestibilidade in vitro e in vivo determinada em ovelhas. A partir daí, a metodologia vem sendo aplicada em muitas avaliações laboratoriais de alimentos.

A técnica se baseia em medidas gravimétricas que segue o desaparecimento do substrato (componentes que podem ou não contribuir para a fermentação) (Getachew et al., 2005). O método apresenta dois estágios onde, inicialmente o alimento é submetido à fermentação em solução tampão contendo fluido ruminal durante 48 horas, seguido por mais 48 horas de digestão com pepsina em solução ácida, para simular a digestão no abomaso.

Segundo Silva \& Queiroz (2002), o segundo estágio com solução ácida de pepsina, é utilizado para desdobrar as proteínas dos microrganismos que se desenvolveram no processo fermentativo do substrato, no entanto, deixa no resíduo, a parede celular indigerível das bactérias. O problema foi solucionado com a modificação proposta por Goering \& Van Soest (1970), em que a digestão com pepsina é abolida e após a etapa fermentativa (48 horas de incubação) o resíduo passa por um tratamento com solução de detergente neutro, resultando em um resíduo constituído apenas por parede indigestível, 
estimando assim, a digestibilidade da matéria seca verdadeira. Essa modificação reduz em cerca $30 \%$ o tempo requerido para obtenção dos resultados, porém não apresenta vantagem no que diz respeito a reprodutibilidade e precisão quando comparado com experimentos in vivo (Menke et al., 1979).

O método tornou-se uma ferramenta importante na avaliação de alimentos para ruminantes e tem sido amplamente usado devido sua conveniência, particularmente quando é requerido um ensaio em grande escala de alimentos para animais (Getachew et al., 1998). As diversas modificações feitas no procedimento original visaram maximizar o processo de digestão visto que os sistemas in vitro que não maximizam a cinética da digestão podem não detectar diferenças na digestão do substrato (Grant \& Mertens, 1992). Contudo, apesar de o método ter sido validado diversas vezes com valores in vivo (Van Soest, 1994), eles ainda apresentam algumas desvantagens em relação a outras técnicas de avaliação de alimentos como as citadas a seguir: i) fornecem uma medida de ponto final; ii) eles não fornecem informações sobre a cinética da digestão de alimentos; iii) são trabalhosos e consomem tempo; iv) envolvem o uso de líquido ruminal coletado de animais fistulados, não permitindo, portanto, resolver questões públicas sobre o bem-estar animal.

Atualmente, existe disponível no mercado um fermentador ruminal artificial desenvolvido pela Ankom, denominado Incubadora Daisy ${ }^{\mathrm{II}}$ (Ankom Technology Co., Macedon, NY, EUA), apresentando como vantagens a possibilidade de analisar várias amostras ao mesmo tempo, reduzindo o labor empregado nas análises (Adesogan, 2002). Equipamento semelhante à Daisy ${ }^{I I}$ foi desenvolvido por uma indústria brasileira, denominado incubadora TE-150 (Tecnal Equipamentos Científicos, Piracicaba, SP, Brasil).

Alguns estudos comparando os valores de digestibilidade in vitro da matéria seca (DIVMS) obtidos pelo método do fermentador artificial Daisy ${ }^{\mathrm{II}}$ em relação ao método tradicional de Tilley \& Terry (1963) indicaram que estes produzem resultados similares (Mabjeesh et al., 2000; Santos et al., 2000). Entretanto, Silva et al. (2017) observaram valores superiores da DIVMS determinadas pelo fermentador TE-150 e incubadora Daisy ${ }^{\mathrm{II}}$ em relação ao método tradicional de Tilley \& Terry (1963).

\section{Técnicas de produção de gás para avaliação de alimentos}

As técnicas de produção de gás são de grande interesse na avaliação dos sistemas de produção de ruminantes, principalmente em razão da sua capacidade de avaliar a dinâmica de digestão e seu potencial para simular os processos de digestão do rúmen (Czerkawski \& Breckenridge, 1977). A técnica foi originalmente desenvolvida para descrever a taxa e a extensão da fermentação da matéria orgânica (Menke et al., 1979).

Ao contrário das técnicas de digestibilidade, que visam avaliar o desaparecimento do substrato, os métodos de produção de gás medem o aparecimento de produtos da fermentação, como gases $\left(\mathrm{CO}_{2} \mathrm{e}\right.$ $\mathrm{CH}_{4}$ ), ácidos graxos de cadeia curta, $\mathrm{NH}_{3}$ e biomassa microbiana (Makkar et al., 1995). A maior parte do gás produzido é resultado da fermentação de carboidratos a acetato, propionato e butirato (Blummel \& Orskov, 1993), com baixa contribuição da proteína para a produção gás e insignificante a quantidade de gás advindo da gordura (Getachew et al., 1998). Além disso, a quantidade de gás produzido depende da quantidade de substrato fermentado (Davies et al., 2000).

As técnicas de produção de gás possibilitam descrever a cinética da fermentação ruminal, fornecendo a taxa e a extensão da degradação das forrageiras (Getachew et al., 1998), além de medir produtos da fermentação de partes solúveis e insolúveis de substratos. Em situações em que os nutrientes não sejam limitantes, a produção de gás pode ser considerada a medida direta do crescimento microbiano, podendo ser em algumas situações, o melhor índice para medir a energia metabolizável produzida (Pell \& Schofield, 1993).

Para medir essa produção de gás, três abordagens diferentes têm sido usadas: 1) medir o volume de gás a pressão atmosférica constante, 2) medir a pressão do gás a um volume fixo, e 3) medir o número de aumentos de volume necessários para causar uma pequena mudança definitiva de pressão, uma combinação dos métodos 1 e 2 . A escolha do método para medir a produção de gás depende da suposição de que os excessos da pressão acumulada afetam o crescimento microbiano (Schofield \& Pell, 1995) e geram mudanças na solubilidade de gases no meio, o que pode gerar erros nas medições (Getachew et al., 1998). 
Essas técnicas têm despertado o interesse de pesquisadores de diferentes áreas e disciplinas, que estudam os impactos diretos da produção animal no meio ambiente (Krishnamoorthy et al., 2005). Esse interesse surgiu principalmente por volta dos anos 70, onde pesquisadores descobriram que medidas de fermentação de substratos a gases combinadas com dados de composição química da dieta poderiam ser usadas para estimar tanto o conteúdo de energia metabolizável como a degradabilidade da matéria orgânica (Yáñez-Ruiz et al., 2016). A partir daí, foram desenvolvidas técnicas para avaliar não só a digestibilidade de um alimento como também os parâmetros cinéticos da digestão, baseados na liberação dos produtos da fermentação.

Czerkawski \& Breckenridge (1975) desenvolveram um sistema que envolvia o registro do deslocamento direto de um pistão, por gases produzidos durante a fermentação de alimentos pelo fluido ruminal em uma seringa de vidro, que se tornou, posteriormente, a base do "teste de gás de Hohenheim" desenvolvido por Menke et al. (1979). O teste de gás de Hohenheim (Menke et al., 1979), consiste na medida direta da produção total de gás liberada pela fermentação, realizada em seringas de vidro fosco (capacidade de $100 \mathrm{ml}$ ), contendo $200 \mathrm{mg}$ de alimento incubado com líquido ruminal tamponado (Figura 1). À medida que o substrato é fermentado, são produzidos gases e o êmbolo da seringa é forçado a subir no interior do cano (Theodorou et al., 1994). Este sistema de avaliação combina o volume total de gases produzidos após 24 h de incubação com a concentração de proteína bruta $(\mathrm{PB})$, gordura bruta, fibra bruta e cinzas da ração para prever a energia metabolizável (EM) (Williams, 2000).

O teste é semelhante ao sistema de Tilley \& Terry (1963), onde o substrato é incubado com líquido ruminal, sendo a principal diferença entre os métodos, o fato de a produção de gás ao invés de perda de matéria seca, descreve a quantidade de substrato fermentado. Embora os autores tenham verificado uma boa correlação entre os dados de produção de gás 24 horas e os valores de digestibilidade determinada in vivo, concluiu-se que um alimento com uma taxa de produção de gás baixa pode ter uma maior digestibilidade in vivo do que o sugerido pelos dados de produção de gás.

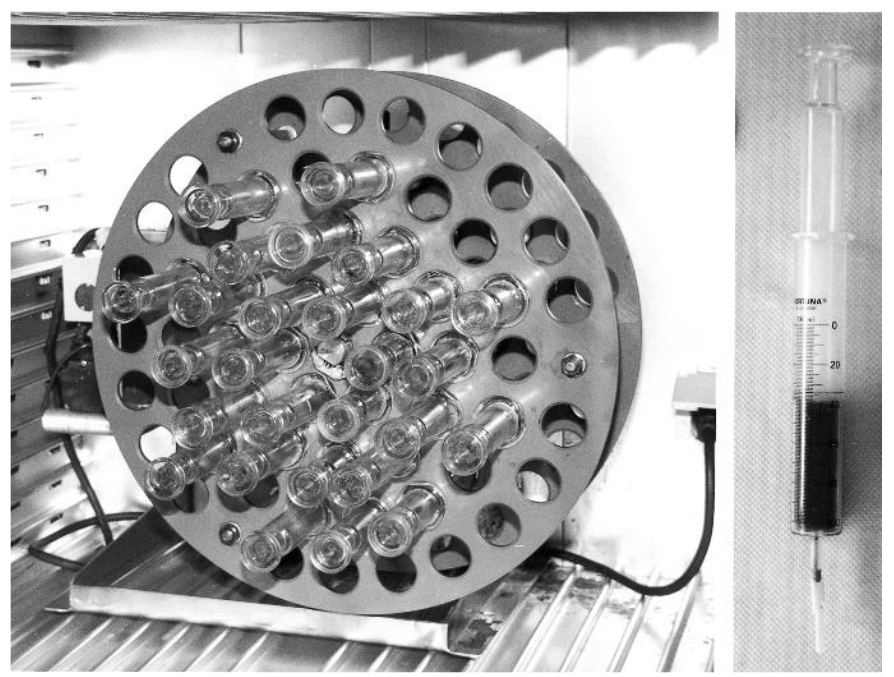

Figura 1. Equipamento para o teste de gás Hohenheim.

O teste de gás de Hohenheim, por sua vez, pode ser adaptado para refletir a extensão e a taxa da fermentação, pela simples leitura do aumento na produção de gás indicado pela subida do êmbolo em uma série de intervalos de tempo escolhidos. Sendo assim, Blummel \& Orskov (1993) realizaram uma modificação no método de Menke et al. (1979) visando avaliar a cinética de produção de gás in vitro. Nesse novo procedimento, as seringas foram incubadas em banho-maria coberto com uma tampa de acrílico equipada com orifícios para manter as seringas eretas no banho-maria. Além disso, ao invés de uma única leitura dos gases, realizada 24 horas após a incubação, a produção de gás foi registrada nos tempos 4, 6, 8, 12, 24, 36, 48 e 72 horas. Os autores observaram que a produção de gás, registrada em diferentes intervalos de tempo, ajustou-se bem aos resultados da técnica do saco de náilon utilizando o mesmo material relatado anteriormente por Ørskov et al. (1988). 
O uso de sistemas manuais utilizados para avaliar tanto a digestibilidade como a cinética de degradação dos alimentos apresentam resultados satisfatórios e são bem correlacionados com valores obtidos in situ e in vivo. Contudo, eles requerem um trabalho pesado para manipulação manual de seringas e dependem de uma boa precisão da leitura dos volumes de gás dentro de seringas (Cone et al., 1996), o que pode afetar potencialmente o perfil de produção de gás de um alimento (Rymer et al., $\underline{2005}$.

\section{- Técnicas de produção de gás semiautomáticas e automáticas}

Durante anos, a produção de gás foi medida manometricamente (Czerkawski \& Breckenridge, 1977; McBee, 1953) e volumetricamente (Menke \& Steingass, 1988), com registros manuais dos resultados. O método manométrico de medição de gás desenvolvido por McBee (1953) permitiu aos autores avaliar a atividade microbiana ruminal com relação à fermentação da celulose e hemicelulose, chegando à conclusão de que a taxa de fermentação de vários substratos no rúmen não é constante, mas sujeita a grandes flutuações após mudanças na dieta do animal. Por sua vez, Cone \& Becker (2012) verificaram que a síntese de proteína microbiana no rúmen depende do grau e da taxa de fermentação dos substratos, sendo a maior produção ocorrendo com substratos de fermentação rápida.

Com o avanço das pesquisas, formas alternativas para medir a produção de gás foram desenvolvidas, onde aumentos de pressão foram sendo registrados em sistemas fechados. Com isso, visando desenvolver um método simples para medição de gás e que pudesse diminuir os erros obtidos a partir de leituras manuais da pressão do gás gerado, Wilkins (1974) descreveu um método diferente, onde amostras de ração foram incubadas em vasos fechados, e a produção de gás foi obtida usando um transdutor de pressão que mediu o acúmulo da pressão do gás no headspace do frasco. Posteriormente, a metodologia de Wilkins (1974) foi aperfeiçoada por Pell \& Schofield (1993), sendo os gases acumulados em frascos de volume fixo $(50 \mathrm{~mL})$, cada um com seu próprio agitador. Como o sistema não é ventilado, o gás acumula-se no headspace, durante 48 horas, e a pressão é medida de forma semiautomática a cada hora. Segundo Theodorou et al. (1998), a falta de ventilação do método, poderia resultar na subestimação das medidas, uma vez que, com alimentos altamente e rapidamente fermentáveis (isto é concentrados), altas pressões podem ser geradas dentro do sistema, o que poderia perturbar e reduzir a atividade microbiana do fluido ruminal. Segundo Cattani et al. (2014), a subestimação da produção de gás in vitro em sistemas fechados, o qual ocorre altas pressões, está relacionado ao fato de uma parte do $\mathrm{CO}_{2}$ ser dissolvida no fluido de fermentação, levando a uma possível superestimação da proporção de $\mathrm{CH}_{4}$ no gás total.

Em função disso, Theodorou et al. (1994) descreveram um método de produção de gás, o qual usava um transdutor de pressão e um conjunto de seringa à prova de gás para medir e liberar as pressões de gases acumuladas dos frascos de cultura de $160 \mathrm{~mL}$. À medida que a fermentação ocorria, o gás era acumulado no headspace das garrafas, sendo ventilado em tempos fixos $(2,4,8,12,24,48$ e 72 horas de incubação) e a produção de gás registrada por um transdutor de pressão ligado a um voltímetro de leitura digital (Figura 2). Este método, apesar de tecnicamente direto, era trabalhoso, uma vez que leituras frequentes eram necessárias, especialmente durante os estágios iniciais da fermentação (Davies et al., 2000).

A técnica desenvolvida por Theodorou et al. (1994) foi modificada por Mauricio et al. (1999), na qual eliminou-se a necessidade de medir o volume de gás com uma seringa, sendo as leituras da pressão do gás no headspace obtidas pela inserção de agulha hipodérmica de um transdutor de pressão manual no frasco de fermentação, conectado a um display visual que faz interface com um computador usando um conversor k485, permitindo a captura direta dos dados (Figura 3). Para descrever o gás acumulado no headspace e o perfil de degradação do substrato, nos termos da taxa fracional dependente do tempo da produção do gás $(\mu)$, fase Lag $(\mathrm{L})$ e potencial de produção de gás/degradação (A). Com essa modificação, foi possível reduzir consideravelmente o tempo necessário e o erro potencial associado à estimativa da quantidade de gases liberados na fermentação, além de ter aumentado substancialmente a capacidade do sistema atual (336 frascos ou 75 substratos + controles por série de incubação). 


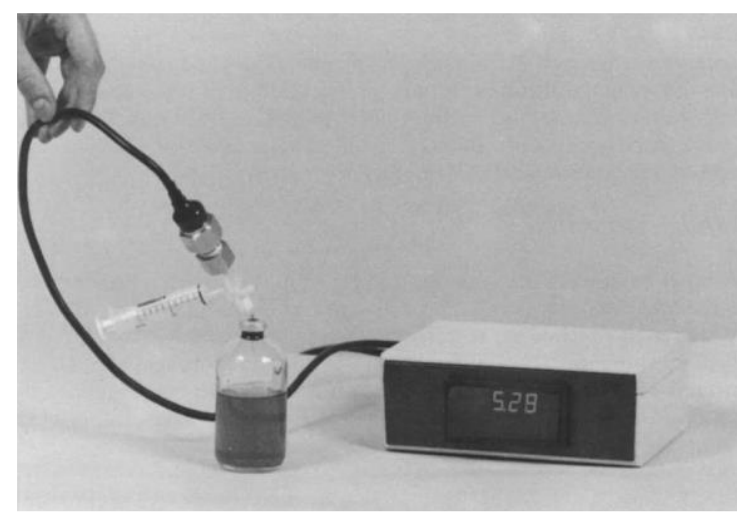

Figura 2. Transdutor de pressão ligado a um voltímetro de leitura digital Fonte: Theodorou et al.(1994)

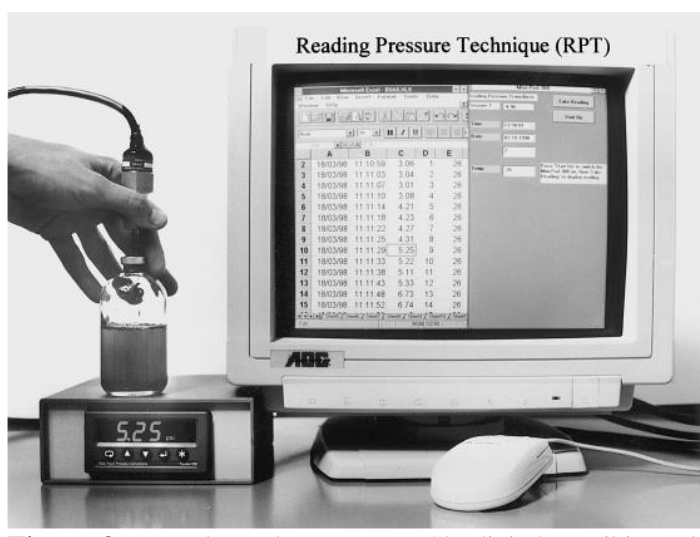

Figura 3. Transdutor de pressão, saída digital e exibição de planilha no computador do sistema RPT (Reading Pressure Technique). Fonte: Mauricio et al. (1999).

Além dos sistemas semiautomáticos, também têm sido desenvolvidos diversos sistemas automatizados para medir a produção de gás. Assim, Beuvink et al. (1992) desenvolveram um sistema de deslocamento de líquido, que utilizou frascos de soro de $100 \mathrm{~mL}$, conectados a garrafas de deslocamento de água e o recipiente de coleta colocado sobre uma balança. As leituras foram feitas a cada 25 minutos quando o peso do líquido deslocado pelo gás foi registrado e armazenado em um datalogger. As garrafas foram mantidas em banho-maria agitado durante a fermentação. No entanto, os sistemas de deslocamento de líquido são tecnicamente difíceis de manter e têm uma resistência interna relativamente alta, introduzindo uma lag time artificial (Cone et al., 1996).

Um sistema de produção de gás relacionado ao tempo totalmente automatizado foi apresentado por Cone et al. (1996) para estudar a cinética de fermentação no fluido ruminal. O sistema faz uso de transdutores eletrônicos de pressão em combinação com válvulas elétricas para liberar a sobre pressão durante a incubação. Pelo fato de ser muito sensível, o sistema não permite que ocorra o acúmulo de gás e de pressão. Cada abertura da válvula representa uma certa quantidade de gás, definida em cerca de 0,7 $\mathrm{mL}$. Registrando o número de aberturas de válvulas no tempo, a cinética da degradação pode ser estudada.

Davies et al. (2000) desenvolveram um sistema de avaliação da pressão automatizado (APES) para medir a produção de gás resultante da fermentação de forragens. O sistema consiste na incubação de 1 $\mathrm{g}$ de substrato teste em frascos de $48 \times 140 \mathrm{~mL}$ contendo $100 \mathrm{~mL}$ de líquido ruminal tamponado. Diferentemente do que ocorre no sistema desenvolvido por Theodorou et al., (1994), o gás acumulado no headspace das garrafas, é liberado automaticamente, pelo uso de chaves sensíveis à pressão e válvulas solenoides, quando uma pressão pré-determinada é atingida. Nesse sistema, a pressão interna nas garrafas nunca ultrapassa o nível definido de $4,5 \mathrm{kPa}$, evitando assim, problemas associados com o aumento da solubilidade do gás a uma pressão aumentada (lei de Henry; Theodorou et al. (1998).

Recentemente a empresa Ankom Tecnology ${ }^{\circledR}$ (Ankom, 2011) desenvolveu um sistema de produção de gás $\left(\mathrm{ANKOM}^{\mathrm{RF}}\right.$ Gas Production System) projetado para medir a cinética da fermentação microbiana de forma automatizada, que possibilita realizar o monitoramento da pressão do gás dentro de múltiplos Módulos, sendo os dados registrados diretamente em planilhas de computador (Figura 4). O sistema tem capacidade para incluir até 50 módulos individuais que comunicam informações a um computador usando transmissão de radiofrequência (RF). A partir da interface do computador, o operador pode controlar diversas variáveis, como intervalos de registro de dados e a liberação automática de pressão pelas válvulas internas em cada módulo.

As principais diferenças entre os sistemas automatizados, diz respeito à suas capacidades e se os frascos são ventilados de acordo com uma dada pressão limiar ou intervalo de tempo (Cone et al., 1996) ou permanecem fechados e a pressão é acumulada no sistema (Pell \& Schofield, 1993). Apesar de suas vantagens na avaliação de alimentos, os sistemas totalmente automatizados apresentam um elevado custo inicial, e sua complexidade e as dificuldades de manutenção tornam estes sistemas inadequados para muitos laboratórios. 
a)

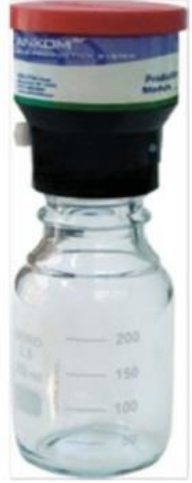

b)
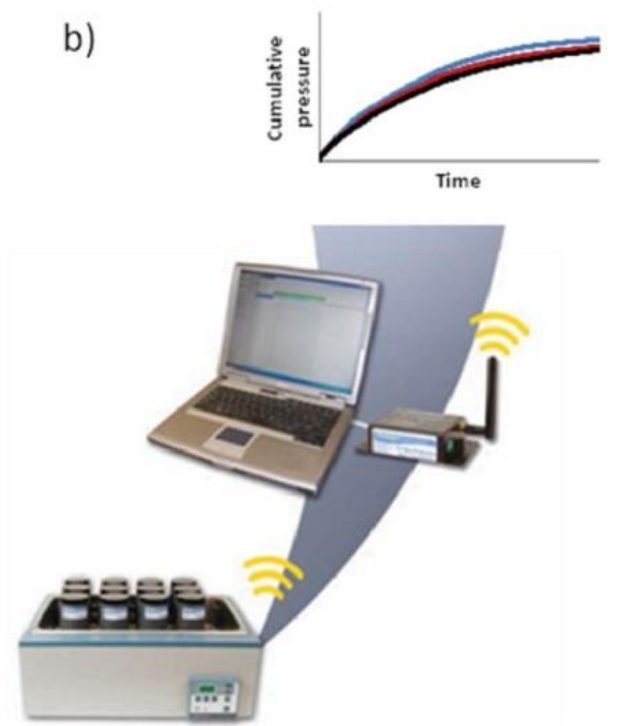

Figura 4. Ilustração de um módulo de produção de gás sem fio in vitro. O módulo individual de produção de gás (a) mede a pressão da fermentação no jarro continuamente e libera gás em um determinado ponto de ajuste acima da pressão atmosférica. Os dados são transferidos sem fio de todos os módulos, que podem ser incubados em banho-maria ou em uma incubadora (b). Fonte: Storm et al. (2012).

Tabela 2 Comparação de sistemas de incubação em métodos de medição de gás comumente usados.

\begin{tabular}{|c|c|c|c|c|c|c|c|c|}
\hline Autores & $\begin{array}{l}\text { Inóculo } \\
\text { Microbiano }\end{array}$ & $\begin{array}{l}\text { Coleta fluido } \\
\text { ruminal }\end{array}$ & $\begin{array}{c}\text { Fluido } \\
\text { ruminal } \\
(\mathrm{mL}) / \\
\text { incubação }\end{array}$ & $\begin{array}{l}\text { Amostra } \\
(\mathrm{mg})\end{array}$ & $\begin{array}{c}\text { Tamanho } \\
\text { container } \\
\text { da } \\
\text { amostra } \\
(\mathrm{mL}) \\
\end{array}$ & $\begin{array}{c}\text { Volume } \\
\text { de } \\
\text { incubação } \\
(\mathrm{mL})\end{array}$ & $\begin{array}{c}\mathrm{N}^{\circ} \mathrm{de} \\
\text { vasos de } \\
\text { fermentaç } \\
\text { ão }\end{array}$ & $\begin{array}{c}\mathrm{HCO}_{3} \\
(\mathrm{mmol}) / \\
\text { incubação }\end{array}$ \\
\hline $\begin{array}{l}\text { Menke et al. } \\
(\underline{1979)}\end{array}$ & Fase Líquida & $\begin{array}{c}\text { Antes da } \\
\text { alimentação }\end{array}$ & 10 & $200-300$ & 100 & 30 & 60 & 2.3 \\
\hline $\begin{array}{l}\text { Beuvink et al. } \\
\text { (1992) }\end{array}$ & Fase Líquida & $\begin{array}{c}\text { Antes da } \\
\text { alimentação }\end{array}$ & 20 & 400 & 100 & 60 & 24 & 4.6 \\
\hline $\begin{array}{l}\text { Pell \& Schofield } \\
(1993)\end{array}$ & Fase Líquida & $\begin{array}{l}2 \mathrm{~h} \text { após } \\
\text { alimentação }\end{array}$ & 2 & 100 & 50 & 9 & 15 & 0.76 \\
\hline $\begin{array}{l}\text { Waghorn \& } \\
\text { Stafford (1993) }\end{array}$ & $\begin{array}{c}\text { Fase Líquida + } \\
\text { Sólida }\end{array}$ & $\begin{array}{l}2 \mathrm{~h} \text { após } \\
\text { alimentação }\end{array}$ & 20 & 1250 & 250 & 80 & $\begin{array}{c}\text { Não } \\
\text { disponível }\end{array}$ & 7.02 \\
\hline Blummel (1994) & $\begin{array}{l}\text { Fase Líquida + } \\
\text { Sólida }\end{array}$ & $\begin{array}{c}\text { Antes da } \\
\text { alimentação }\end{array}$ & 10 & 500 & 100 & 40 & $60-120$ & 4.6 \\
\hline $\begin{array}{l}\text { Theodorou et al. } \\
\text { (1994) }\end{array}$ & $\begin{array}{c}\text { Fase Líquida + } \\
\text { Sólida }\end{array}$ & $\begin{array}{l}\text { Antes da } \\
\text { alimentação }\end{array}$ & 10 & $500-1000$ & 125 & 100 & - & 3.76 \\
\hline $\begin{array}{l}\text { Cone et al. } \\
(1996)\end{array}$ & Fase Líquida & $\begin{array}{c}2 \mathrm{~h} \text { após } \\
\text { alimentação }\end{array}$ & 20 & $400-500$ & 250 & 60 & 12 & 4.6 \\
\hline
\end{tabular}

Adaptado de Getachew et al. (1998).

\section{Considerações finais}

Técnicas in vitro e in situ são amplamente utilizadas para estimar a digestibilidade e a degradabilidade ruminal e estudar a fermentação ruminal. Além disso, os dados in vitro e in situ são úteis para detectar efeitos de tratamento, comparações relativas de alimentos ou, em alguns casos, como características intrínsecas de alimentos que podem ser usados na formulação de dietas.

Diversos sistemas foram desenvolvidos para medir a produção de gás oriundos da fermentação ruminal de substratos. Os sistemas automatizados apresentam vantagem em relação aos sistemas manuais pois permitem a medição do gás de forma ininterrupta, contudo esses sistemas requerem maiores insumos e, portanto, parece ser difícil de adotar como um método de rotina de avaliação de alimentos.

Assim, os métodos não automatizados como aqueles baseados em transdutores de pressão e seringas a gás parecem ser mais adequados, pois são mais baratos e robustos, além de serem capazes de acomodar a determinação de resíduos. 


\section{Referências bibliográficas}

Adesogan, A. T. (2002). What are feeds worth? A critical evaluation of selected nutritive value methods. Proceedings 13th Annual Florida Ruminant Nutrition Symposium, 33-46.

Alamouti, A. A., Ghorbani, G. R., Alikhani, M., Rahmani, H. R., Yansari, A. T., \& Südekum, K. H. (2009). Effects of lucerne particle size and source of dietary carbohydrates on in situ degradation and ruminal variables in sheep. Czech Journal of Animal Science, 54(6), 277-285. https://doi.org/10.17221/1729-CJAS.

Ali, M., Cone, J. W., Van Duinkerken, G., Klop, A., Blok, M. C., Bruinenberg, M., Khan, N. A., \& Hendriks, W. H. (2016). Variation between individual cows in in situ rumen degradation characteristics of maize and grass silages. NJAS-Wageningen Journal of Life Sciences, 78, 167-173. https://doi.org/10.1016/j.njas.2016.05.009.

ANKOM (2011). Disponível em: https://www.ankom.com/sites/default/files/documentfiles/RF_Manual.pdf. Acesso em 15/06/2018.

Australian agricultural Council. Ruminants Subcommittee (AACRS). (1990). Feeding Standars For Australian Livestock: Ruminants. CSIRO Australia.

Azarfar, A., Jonker, A., \& Yu, P. (2013). Assessing protein availability of different bioethanol coproducts in dairy cattle. Animal, 7(2), 255-264. https://doi.org/10.1017/S1751731112001425.

Berchielli, T. T., Sader, A. P. O., Tonani, F. L., Paziani, S. F., \& Andrade, P. (2001). Avaliação da determinação da fibra em detergente neutro e da fibra em detergente ácido pelo sistema ANKOM. Revista Brasileira de Zootecnia, 30(5), 1572-1578. https://doi.org/10.1590/s151635982001000600027.

Beuvink, J. W. M., Spoelstra, S. F., \& Hogendorp, R. J. (1992). An automated method for measuring time-course of gas production of feedstuffs incubated with buffered rumen fluid. NJAS Wageningen Journal of Life Sciences, 40(4), 401-407. https://doi.org//doi.org/10.18174/njas.v40i4.16501.

Blummel, M., \& Orskov, E. R. (1993). Comparison of in vitro gas production and nylon bag degradability of roughages in predicting feed intake in cattle. Animal Feed Science and Technology, 40(2/3), 109-119. https://doi.org/10.1016/0377-8401(93)90150-I.

Carro, M. D., Lebzien, P., \& Rohr, K. (1995). Effects of pore size of nylon bags and dilution rate on fermentation parameters in a semi-continuous artificial rumen. Small Ruminant Research, 15(2), 113-119. https://doi.org/10.1016/0921-4488(94)00015-Y.

Casali, A O, Detmann, E., Valadares Filho, S. C., Pereira, J. C., Henriques, L. T., Freitas, S. G., \& Paulino, M. F. (2008). Influência do tempo de incubação e do tamanho de partículas sobre os teores de compostos indigestíveis em alimentos e fezes bovinas obtidos por procedimentos in situ. Revista Brasileira de Zootecnia, 37(2), 335-342. https://doi.org/http://dx.doi.org/10.1590/S151635982008000200021.

Casali, André Oliveira, Detmann, E., Valadares Filho, S. C., Pereira, J. C., Cunha, M., Detmann, K. da S. C., \& Paulino, M. F. (2009). Estimação de teores de componentes fibrosos em alimentos para ruminantes em sacos de diferentes tecidos. Revista Brasileira de Zootecnia, 38(1), 130-138. https://doi.org/http://dx.doi.org/10.1590/S1516-35982009000100017.

Cattani, M., Tagliapietra, F., Maccarana, L., Hansen, H. H., Bailoni, L., \& Schiavon, S. (2014). In vitro total gas and methane production measurements from closed or vented rumen batch culture systems. Journal of Dairy Science, 97(3), 1736-1741. https://doi.org/10.3168/jds.2013-7462.

Cobellis, G., Acuti, G., Forte, C., Menghini, L., De Vincenzi, S., Orrù, M., Valiani, A., Pacetti, D., \& Trabalza-Marinucci, M. (2015). Use of Rosmarinus officinalis in sheep diet formulations: Effects on ruminal fermentation, microbial numbers and in situ degradability. Small Ruminant Research, 126, 10-18. https://doi.org/10.1016/j.smallrumres.2015.01.018.

Cone, J. W., \& Becker, P. M. (2012). Fermentation kinetics and production of volatile fatty acids and microbial protein by starchy feedstuffs. Animal Feed Science and Technology, 172(1-2), 34-41. https://doi.org/10.1016/j.anifeedsci.2011.12.006.

Cone, J. W., van Gelder, A. H., Visscher, G. J. W., \& Oudshoorn, L. (1996). Influence of rumen fluid and substrate concentration on fermentation kinetics measured with a fully automated time related 
gas production apparatus. Animal Feed Science and Technology, 61(1-4), 113-128. https://doi.org/10.1016/0377-8401(96)00950-9.

Czerkawski, J. W., \& Breckenridge, G. (1975). New inhibitors of methane production by rumen microorganisms. Development and testing of inhibitors in vitro. British Journal of Nutrition, 34(3), 429446. https://doi.org/10.1017/s0007114575000499

Czerkawski, J. W., \& Breckenridge, G. (1977). Design and development of a long-term rumen simulation technique (Rusitec). British Journal of Nutrition, 38(3), 371-384. https://doi.org/10.1079/BJN19770102.

Damiran, D., DelCurto, T., Bohnert, D. W., \& Findholt, S. L. (2008). Comparison of techniques and grinding size to estimate digestibility of forage based ruminant diets. Animal Feed Science and Technology, 141(1-2), 15-35. https://doi.org/10.1016/j.anifeedsci.2007.04.007.

Davies, Z. S., Mason, D., Brooks, A. E., Griffith, G. W., Merry, R. J., \& Theodorou, M. K. (2000). An automated system for measuring gas production from forages inoculated with rumen fluid and its use in determining the effect of enzymes on grass silage. Animal Feed Science and Technology, 83(34), 205-221. https://doi.org/http://dx.doi.org/10.1016/S0377-8401(99)00138-8

Dijkstra, J., Forbes, J. M., \& France, J. (2005). Quantitative aspects of ruminant digestion and metabolism. CABI.

Dong, S., Azarfar, A., Yang, Z. O. U., LI, S., Wang, Y., \& Cao, Z. (2017). Effects of sequence of nylon bags rumen incubation on kinetics of degradation in some commonly used feedstuffs in dairy rations. Journal of IItegrative Agriculture, 16(1), 162-168. https://doi.org/10.1016/S2095-3119(16)614387.

Edmunds, B., Südekum, K.-H., Spiekers, H., \& Schwarz, F. J. (2012). Estimating ruminal crude protein degradation of forages using in situ and in vitro techniques. Animal Feed Science and Technology, 175(3-4), 95-105. https://doi.org/10.1016/j.anifeedsci.2012.04.003.

Figroid, W., Hale, W. H., \& Theurer, B. (1972). An evaluation of the nylon bag technique for estimating rumen utilization of grains. Journal of Animal Science, 35(1), 113-120. https://doi.org/10.2527/jas1972.351113x.

Getachew, G., Blümmel, M., Makkar, H. P. S., \& Becker, K. (1998). In vitro gas measuring techniques for assessment of nutritional quality of feeds: a review. Animal Feed Science and Technology, 72(3), 261-281.

Getachew, G., DePeters, E. J., Robinson, P. H., \& Fadel, J. G. (2005). Use of an in vitro rumen gas production technique to evaluate microbial fermentation of ruminant feeds and its impact on fermentation products. Animal Feed Science and Technology, 123-124, P(0), 547-559. https://doi.org/http://dx.doi.org/10.1016/j.anifeedsci.2005.04.034

Goering, H. K., \& Van Soest, P. J. (1970). Forage Fiber Analysis. USDA Agricultural Research Service. Handbook number 379. In US Department of Agriculture. Superintendent of Documents, (16th ed.). US Government Printing Office.

Grant, R. J., \& Mertens, D. R. (1992). Impact of in vitro fermentation techniques upon kinetics of fiber digestion. Journal of Dairy Science, 75(5), 1263-1272. https://doi.org/10.3168/jds.S00220302(92)77876-X.

Huntingdon, J. A., \& Givens, D. I. (1995). The in situ technique for studying the rumen degradation of feeds: a review of the procedure. Nutrition Abstracts and Reviews, 65, 63-93.

Jonker, A., Gruber, M. Y., Wang, Y., Coulman, B., Azarfar, A., McKinnon, J. J., Christensen, D. A., \& Yu, P. (2011). Modeling degradation ratios and nutrient availability of anthocyanidin-accumulating Lc-alfalfa populations in dairy cows. Journal of Dairy Science, 94(3), 1430-1444. https://doi.org/10.3168/jds.2010-3604.

Krishnamoorthy, U., Rymer, C., \& Robinson, P. H. (2005). The in vitro gas production technique: Limitations and opportunities. Animal Feed Science and Technology. https://doi.org/10.1016/j.anifeedsci.2005.04.015.

Kuwahara, F. A., Souza, G. B. de, Ferreira, R. de P., Costa, C., \& Meirelles, P. R. de L. (2016). Evaluation in situ digestibility of alfalfa in different grinds and textiles. Acta Scientiarum. Animal 
Sciences, 38(1), 37-43. https://doi.org/10.4025/actascianimsci.v38i1.28867.

Lindberg, J. E. (1981). The effect of basal diet on the ruminal degradation of dry matter, nitrogenous compounds and cell walls in nylon bags. Roughage and cereals in various proportions. Swedish Journal of Agricultural Research, 11, 159-169.

Lindberg, J. E., \& Knutsson, P.-G. (1981). Effect of bag pore size on the loss of particulate matter and on the degradation of cell wall fibre. Agriculture and Environment, 6(2-3), 171-182. https://doi.org/10.1016/0304-1131(81)90009-6.

Mabjeesh, S. J., Cohen, M., \& Arieli, A. (2000). In vitro methods for measuring the dry matter digestibility of ruminant feedstuffs: comparison of methods and inoculum source. Journal of Dairy Science, 83(10), 2289-2294. https://doi.org/10.3168/jds.S0022-0302(00)75115-0.

Makkar, H. P. S., Blümmel, M., \& Becker, K. (1995). Formation of complexes between polyvinyl pyrrolidones or polyethylene glycols and tannins, and their implication in gas production and true digestibility in in vitro techniques. British Journal of Nutrition, 73(6), 897-913. https://doi.org/10.1079/bjn19950095.

Marinucci, M. T., Dehority, B. A., \& Loerch, S. C. (1992). In vitro and in vivo studies of factors affecting digestion of feeds in synthetic fiber bags. Journal of Animal Science, 70(1), 296-307. https://doi.org/10.2527/1992.701296x.

Mauricio, R. M., Moulda, F. L., Dhanoab, M. S., Owena, E., Channaa, K. S., \& Theodorou, M. K. (1999). A semi-automated in vitro gas production technique for ruminant feedstuff evaluation. Animal Feed Science and Technology, 79(4), 321-330. https://doi.org/10.1016/S03778401(99)00033-4.

McBee, R. H. (1953). A Manometric Method for the Evaluation of the Microbial Activity of the Rumen with an Application to the Utilization of Cellulose and Hemicelluloses. Applied Microbiology, 1(2), 106. https://doi.org/10.1128/aem.1.2.106-110.1953.

Menke, K. H., Raab, L., Salewski, A., Steingass, H., Fritz, D., \& Schneider, W. (1979). The estimation of the digestibility and metabolizable energy content of ruminant feedingstuffs from the gas production when they are incubated with rumen liquor in vitro. The Journal of Agricultural Science, 93(1), 217-222.

Menke, K. H., \& Steingass, H. (1988). Estimation of the energetic feed value obtained from chemical analysis and in vitro gas production using rumen fluid. Animal Research Development, 28, 7-55.

Michalet-Doreau, B., \& Ould-Bah, M. Y. (1992). In vitro and in sacco methods for the estimation of dietary nitrogen degradability in the rumen: a review. Animal Feed Science and Technology, 40(1), 57-86. https://doi.org/10.1016/0377-8401(92)90112-J.

Nocek, J. E. (1985). Evaluation of specific variables affecting in situ estimates of ruminal dry matter and protein digestion. Journal of Animal Science, 60(5), 1347-1358.

Nocek, J. E. (1988). In situ and other methods to estimate ruminal protein and energy digestibility: a review. Journal of Dairy Science, 71(8), 2051-2069. https://doi.org/http:dx.doi.org/10.3168/jds.S0022-0302(88)79781-7.

Offner, A., Bach, A., \& Sauvant, D. (2003). Quantitative review of in situ starch degradation in the rumen. Animal Feed Science and Technology, 106(1-4), 81-93. https://doi.org/http://dx.doi.org/10.1016/S0377-8401(03)00038-5

Ørskov, E. R., \& McDonald, I. (1979). The estimation of protein degradability in the rumen from incubation measurements weighted according to rate of passage. The Journal of Agricultural Science, 92(2), 499-503. https://doi.org/https://doi.org/10.1017/S0021859600063048.

Ørskov, E. R., Reid, G. W., \& Kay, M. (1988). Prediction of intake by cattle from degradation characteristics of roughages. Animal Science, 46(1), 29-34. https://doi.org/10.1017/S000335610000307X.

Pagella, J. H., Mayes, R. W., Pérez-Barbería, F. J., \& Ørskov, E. R. (2018). The development of an intraruminal nylon bag technique using non-fistulated animals to assess the rumen degradability of dietary plant materials. Animal, 12(1), 54-65. https://doi.org/10.1017/S1751731117001203. 23.

Pell, A. N., \& Schofield, P. (1993). Computerized monitoring of gas production to measure forage 
digestion in vitro. Journal of Dairy Science, 76(4), 1063-1073.

Peyrat, J., Nozière, P., Le Morvan, A., Férard, A., Protin, P.-V., \& Baumont, R. (2014). Effects of ensiling maize and sample conditioning on in situ rumen degradation of dry matter, starch and fibre. Animal Feed Science and Technology, 196, 12-21. https://doi.org/10.1016/j.anifeedsci.2014.06.017.

Quin, J. I., Van der Wath, J. G., \& Myburgh, S. (1938). Studies on the alimentary tract of Merido sheep in South Africa. 4. Description of experimental technique. Onderstepoort Journal of Veterinary Science and Animal Industry, 11, 341-360.

Robles, A. Y., Belyea, R. L., Martz, F. A., \& Weiss, M. F. (1980). Effect of particle size upon digestible cell wall and rate of in vitro digestion of alfalfa and orchardgrass forages. Journal of Animal Science, 51(4), 783-790. https://doi.org/10.2527/jas1980.514783x.

Rodriguez, H. (1968). The in vivo bag technique in digestibility studies. Revista Cubana de Ciência Agrícola, 2, 77-81.

Rymer, C., Huntington, J. A., Williams, B. A., \& Givens, D. I. (2005). In vitro cumulative gas production techniques: History, methodological considerations and challenges. Animal Feed Science and Technology, 123, 9-30. https://doi.org/10.1016/j.anifeedsci.2005.04.055.

Santos, G. T., Assis, M. A., Gonçalves, G. D., Modesto, E. C., Cecato, U., Jobim, C. C., \& Damasceno, J. C. (2000). Determinação da digestibilidade in vitro de gramíneas do gênero Cynodon com uso de diferentes metodologias. Acta Scientiarum. Animal Sciences, 22, 761-764. https://doi.org/10.4025/actascianimsci.v22i0.3187.

Sauvant, D., Chapoutot, P., \& Archimède, H. (1994). La digestion des amidons par les ruminants et ses conséquences. INRA Productions Animales, 7(2), 115-124.

Schofield, P., \& Pell, A. N. (1995). Validity of using accumulated gas pressure readings to measure forage digestion in vitro: a comparison involving three forages. Journal of Dairy Science, 78(10), 2230-2238. https://doi.org/10.3168/jds.S0022-0302(95)76850-3.

Silva, D. J., \& Queiroz, A. C. (2002). Análise de alimentos: métodos químicos e biológicos (3rd ed.). Universdiade Federal de Viçosa.

Silva, T. E., Detmann, E., Camacho, L. F., Saliba, E. O. S., Palma, M. N. N., \& Valadares Filho, S. C. (2017). Comparação de métodos in vitro para a quantificação da digestibilidade da matéria seca e da fibra em detergente neutro de forragens e concentrados. Arquivo Brasileiro de Medicina Veterinária e Zootecnia, 69(6), 1635-1644. https://doi.org/10.1590/1678-4162-9096.

St-Pierre, N. R. (2001). Invited review: Integrating quantitative findings from multiple studies using mixed model methodology. Journal of Dairy Science, 84(4), 741-755. https://doi.org/10.3168/jds.S0022-0302(01)74530-4.

Storm, A. C., Kristensen, N. B., \& Hanigan, M. D. (2012). A model of ruminal volatile fatty acid absorption kinetics and rumen epithelial blood flow in lactating Holstein cows. Journal of Dairy Science, 95(6), 2919-2934. https://doi.org/http://dx.doi.org/10.3168/jds.2011-4239

Tagliapietra, F., Cattani, M., Hindrichsen, I. K., Hansen, H. H., Colombini, S., Bailoni, L., \& Schiavon, S. (2012). True dry matter digestibility of feeds evaluated in situ with different bags and in vitro using rumen fluid collected from intact donor cows. Animal Production Science, 52(5), 338-346. https://doi.org/10.1071/AN11206.

Theodorou, M K, Lowman, R. S., Davies, Z. S., Cuddeford, D., \& Owen, E. (1998). Principles of techniques that rely on gas measurements in ruminant nutrition. British Society of Animal Science, 22(1), 55-64.

Theodorou, Michael K, Williams, B. A., Dhanoa, M. S., McAllan, A. B., \& France, J. (1994). A simple gas production method using a pressure transducer to determine the fermentation kinetics of ruminant feeds. Animal Feed Science and Technology, 48(3), 185-197.

Tilley, J. M. A., \& Terry, R. A. (1963). A two-stage technique for the in vitro digestion of forage crops. Grass and Forage Science, 18(2), 104-111.

Uden, P., Parra, R., \& Van Soest, P. J. (1974). Factors influencing reliability of the nylon bag technique. Journal of Dairy Science, 57, 622.

Valente, T. N. P., Detmann, E., Valadares Filho, S. de C., Queiroz, A. C. de, Sampaio, C. B., \& Gomes, 
D. I. (2011). Avaliação dos teores de fibra em detergente neutro em forragens, concentrados e fezes bovinas moídas em diferentes tamanhos e em sacos de diferentes tecidos. Revista Brasileira de Zootecnia, 40(5), 1148-1154. https://doi.org/10.1590/S1516-35982011000500029.

Van Soest, P. J. (1994). Nutritional ecology of the ruminant. In Nutritional Ecology of the Ruminant (Vol. 1, Issue 2). Cornell University Press. https://doi.org/10.7591/9781501732355

Waghorn, G.C., \& Stafford, K.J. (1993). Gas production and nitrogen digestion by rumen microbes from deer and sheep. New Zealand Journal of Agricultural Research, 36, 493-497. https://doi.org/10.1080/00288233.1993.10417750.

Wilkins, J. R. (1974). Pressure transducer method for measuring gas production by microorganisms. Applied Microbiology, 27(1), 135-140. https://doi.org/10.1128/aem.27.1.135-140.1974.

Williams, B. A. (2000). Cumulative gas-production techniques for forage evaluation. In D. I. Givens, E. Owen, R. F. E. Axford, \& H. M. Omed (Eds.), Forage Evaluation in Ruminant Nutrition. CAB International, Wallingford, UK. CAB International.

Xin, H., \& Yu, P. (2013). Using ATR-FT/IR to detect carbohydrate-related molecular structure features of carinata meal and their in situ residues of ruminal fermentation in comparison with canola meal. Spectrochimica Acta Part A: Molecular and Biomolecular Spectroscopy, 114, 599-606. https://doi.org/10.1016/j.saa.2013.05.056.

Yáñez-Ruiz, D. R., Bannink, A., Dijkstra, J., Kebreab, E., Morgavi, D. P., O’Kiely, P., Reynolds, C. K., Schwarm, A., Shingfield, K. J., \& Yu, Z. (2016). Design, implementation and interpretation of in vitro batch culture experiments to assess enteric methane mitigation in ruminants - a review. Animal Feed Science and Technology, 216, 1-18. https://doi.org/10.1016/j.anifeedsci.2016.03.016.

Histórico do artigo:

Recebido: 29 de maio de 2021

Aprovado: 5 de julho de 2021
Licenciamento: Este artigo é publicado na modalidade Acesso Aberto sob a licença Creative Commons Atribuição 4.0 (CC-BY 4.0), a qual permite uso irrestrito, distribuição, reprodução em qualquer meio, desde que o autor e a fonte sejam devidamente creditados. 